\title{
Curriculum Mapping Across the Disciplines: Differences, Approaches, and Strategies
}

Fiona Rawle, Tracey Bowen, Barbara Murck, and Rosa Junghwa Hong University of Toronto Mississauga

DOI: $10.22329 /$ celt.v10i0.4765

Curriculum mapping can be used to document, align, visualize, and assess curricular data, such as learning outcomes, assessment materials, instructional techniques, and student pre-and post-testing scores. A cross-disciplinary Curriculum Mapping Initiative currently underway at the University of Toronto Mississanga aims to: (1) develop guidelines for the curriculum mapping process; (2) develop cross-disciplinary curriculum mapping templates and samples to guide departments through the curriculum mapping process; (3) communicate narratives for how to use curriculum mapping to inform curricular change; (4) develop visualization strategies for curricular data; (5) initiate a plan for dissemination and sustainability; and (6) initiate a plan for informing students about how to use curricular maps in their academic experiences. Through this curriculum mapping initiative, we have discovered that discipline-specific differences exist in approaches to curriculum mapping. The purpose of this paper is to communicate these cross-disciplinary similarities and differences in purpose, process, and utilization of curriculum mapping strategies. We found that different departments had some common ground in the curriculum mapping process, but also key differences. The differences could be categorized according to: purpose for initiating the curriculum mapping process; approach to curriculum mapping; dissemination of completed maps; dealing with pedagogical jargon; and faculty buy-in.

C urriculum mapping is an active process for aligning student learning outcomes and curriculum activities (Kopera-Frye, Mahaffy, \& Svare, 2008). Much has been written in the literature regarding the curriculum mapping process, especially in the medical and engineering disciplines (French, Shah, Rankin, Bagiati, \& Breslow, 2012; Komenda et al., 2015). Curriculum mapping is often undertaken to assist with accreditation procedures (DeLuca \& Bellara, 2013; Kelley, McAuley, Wallace, \& Frank, 2008; Perlin, 2011), or for formalized curricular review and improvement (Veltri, Webb, Matveev, \& Zapatero, 2011). Curriculum mapping can be used to map learning outcomes throughout a single course or across programs, to map course progression, to track both the teaching and assessment of student learning outcomes, or as part of the curricular alignment process (Lam \& Tsui, 2013). Curriculum mapping can also be used to identify gaps (Lam \& Tsui, 2013), and can lead to increased transparency (Harden, 2001). 


\section{The Curriculum Mapping Initiative at the University of Toronto Mississauga}

A cross-disciplinary curriculum mapping initiative at the University of Toronto Mississauga is focused on: (1) developing guidelines for the curriculum mapping process; (2) developing cross-disciplinary curriculum mapping templates and samples that can guide other departments through the curriculum mapping process; (3) communicating strategies for how to use curriculum mapping to inform curricular change; (4) developing curricular visualizations; (5) initiating a plan for dissemination and sustainability, with a focus on continuing the curriculum mapping process at the University of Toronto Mississauga, and (6) initiating a plan for informing students about curricular maps, and how they can use the maps throughout their academic experiences. Participating departments (initially Biology, Geography, Sociology, Historical Studies, Language Studies, and Institute of Communication, Culture, Information and
Technology) were specifically chosen to represent a cross-disciplinary diversity, as well as a wide range in terms of how much progress had already been made in the curriculum mapping process at the developmental level.

\section{Curriculum Mapping in the Literature}

In order to see what different disciplines had previously reported regarding curriculum mapping, we did a thorough literature review. Prior to initiating our literature search, the search strategy and search string were approved by an independent liaison librarian. The search string "curriculum map" was searched in September 2016 in the following databases: ProQuest Education Journals (limit to scholarly journals), Scopus, ERIC, CBCA Education, PsycINFO, and Web of Science. Removal of duplicates resulted in 597 unique results.

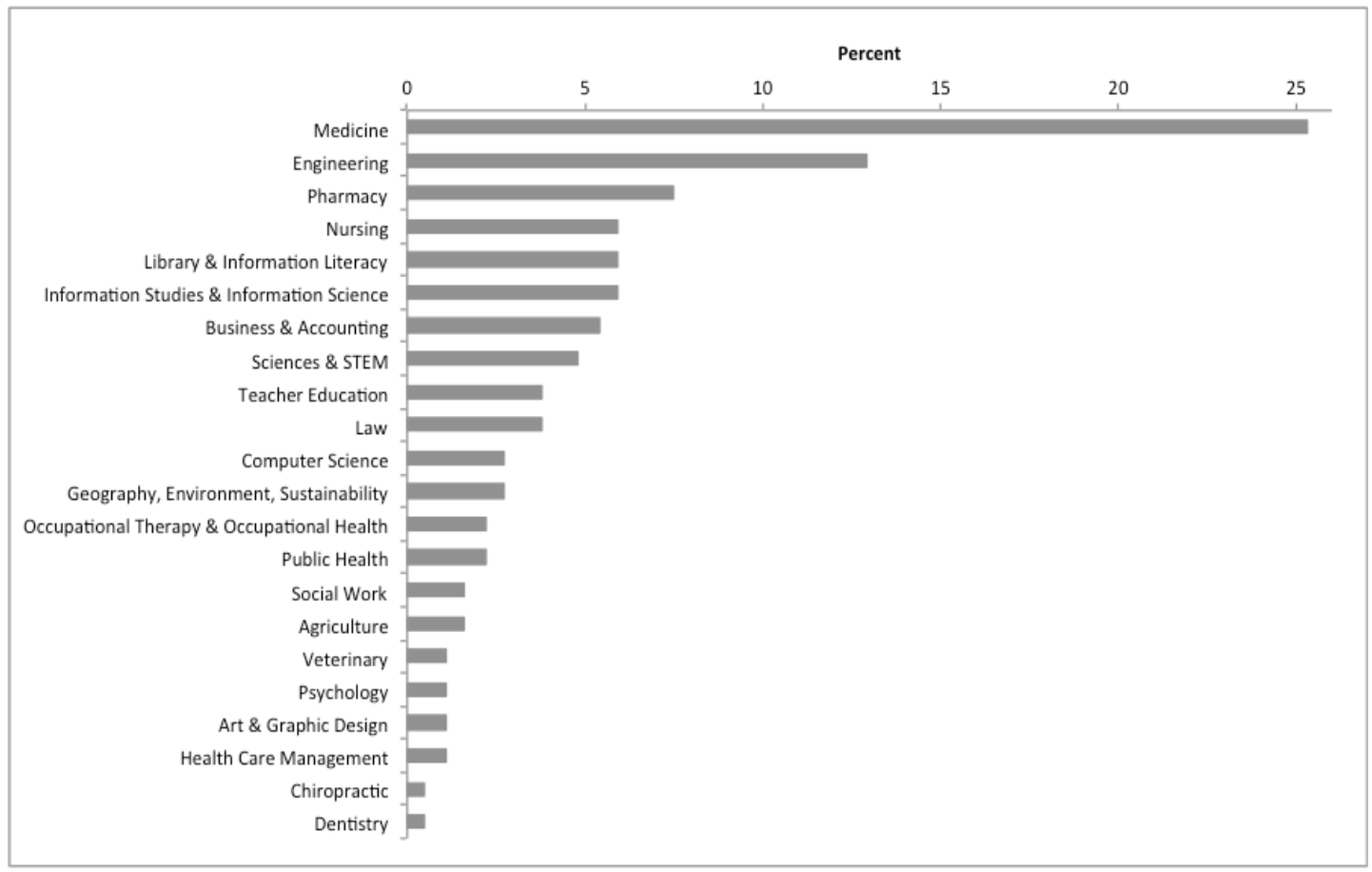

Figure 1

Percentage of Scholarly Publications devoted to curriculum mapping in higher education, sorted by discipline. ${ }^{1}$

\footnotetext{
${ }^{1}$ The search string "curriculum map*" was searched in ProQuest Education Journals (limit to scholarly journals), Scopus, ERIC, CBCA Education, PsycINFO, and Web of Science. Removal of duplicates resulted in 597 unique results, and subsequent removal of articles not in the higher education context resulted in 185 discipline-specific references.
} 


\section{Table 1}

Curriculum mapping in higher education: publications by discipline in the literature $(n=185)$.

\begin{tabular}{|c|c|c|c|}
\hline Discipline & Total No. & $\%$ & Sample Reference(s) \\
\hline Medicine & 47 & 25.3 & $\begin{array}{l}\text { (Balzer et al., 2016; Cottrell, Linger, \& Shumway, 2004; Ellaway, Albright, Smothers, } \\
\text { Cameron, \& Willett, 2014; Harden, 2001; May, 2012; Wardle et al., 2011; Willett, 2008; } \\
\text { Wong \& Roberts, 2007) }\end{array}$ \\
\hline Engineering & 24 & 12.9 & $\begin{array}{l}\text { (Ahmad, 2015; Cloutier, Hugo, \& Sellens, 2012; French et al., 2012; Joenathan, Bunch, } \\
\text { \& Granieri, 2005; Liu, Chen, Yueh, \& Sheen, 2014; Ranade et al., 2011; Saad, 2014) }\end{array}$ \\
\hline Pharmacy & 14 & 7.5 & $\begin{array}{l}\text { (Britton, Letassy, Medina, \& Er, 2008; Keijsers et al., 2015; Kelley et al., 2008; Malone, } \\
\text { Short, Naidu, White, \& Kirkpatrick, 2015; Plaza, Draugalis, Slack, Skrepnek, \& Sauer, } \\
\text { 2007; Zelenitsky et al., 2014) }\end{array}$ \\
\hline Nursing & 11 & 5.9 & $\begin{array}{l}\text { (Landry et al., 2011; Miller \& Neyer, 2016; Narayanasamy, Jurgens, Narayanasamy, \& } \\
\text { Guo, 2013) }\end{array}$ \\
\hline $\begin{array}{l}\text { Library \& Information } \\
\text { Literacy }\end{array}$ & 11 & 5.9 & $\begin{array}{l}\text { (Archambault \& Masunaga, 2015; Buchanan, Webb, Houk, \& Tingelstad, 2015; } \\
\text { Charles, 2015; Fournier, 2014) }\end{array}$ \\
\hline $\begin{array}{l}\text { Information Studies \& } \\
\text { Information Science }\end{array}$ & 11 & 5.9 & (Karsten \& Roth, 2015; McGrath, 2010; Pratt, Keys, \& Wirkus, 2014; Veltri et al., 2011) \\
\hline Business \& Accounting & 10 & 5.4 & (Wang \& Ashcraft, 2012) \\
\hline Sciences \& STEM & 9 & 4.8 & (Johnson, Peters-Burton, \& Moore, 2015; Regier, 2015; Reid \& Wilkes, 2016) \\
\hline Teacher Education & 7 & 3.8 & (Baecher, 2012; Rowley \& Dunbar-Hall, 2012; Lam \& Tsui, 2013) \\
\hline Law & 7 & 3.8 & (Curtis \& Moss, 2010) \\
\hline Computer Science & 5 & 2.7 & (Gluga, 2010; Harris \& Patten, 2015) \\
\hline $\begin{array}{l}\text { Geography, Environment, } \\
\text { Sustainability }\end{array}$ & 5 & 2.7 & (Spronken-Smith et al., 2016) \\
\hline $\begin{array}{l}\text { Occupational Therapy \& } \\
\text { Occupational Health }\end{array}$ & 4 & 2.2 & $\begin{array}{l}\text { (MacNeil \& Hand, 2014; Hege, Nowak, Kolb, Fischer, \& Radon, 2010; Merritt, Blake, } \\
\text { McIntyre, \& Packer, 2012) }\end{array}$ \\
\hline Public Health & 4 & 2.2 & $\begin{array}{l}\text { (Britten, Wallar, McEwen, \& Papadopoulos, 2014; Figueroa, Birch, King, \& Cottrell, } \\
\text { 2015) }\end{array}$ \\
\hline Social Work & 3 & 1.6 & (Mackie \& Anderson, 2011; Watts \& Hodgson, 2015; Williams \& Bolland, 2011) \\
\hline Agriculture & 3 & 1.6 & (Acuña, Kelder, Lane, Hannan, \& Jones, 2013) \\
\hline Veterinary & 2 & 1.1 & (Bell, Ellaway, \& Rhind, 2009) \\
\hline Psychology & 2 & 1.1 & (Stanny, 2015) \\
\hline Art \& Graphic Design & 2 & 1.1 & (Lamb, 2016) \\
\hline Health Care Management & 2 & 1.1 & (Valerius \& Hersh, 2008) \\
\hline Chiropractic & 1 & 0.5 & (Gorrell, Beirman, \& Vemulpad, 2015) \\
\hline Dentistry & 1 & 0.5 & (Mazurat \& Schönwetter, 2008) \\
\hline
\end{tabular}


We manually reviewed all articles and set a restriction to articles dealing with the higher education context, resulting in 185 discipline-specific references for curriculum mapping in higher education. We then categorized these references by discipline, as seen in Figure 1 and Table 1. Medicine and engineering were the dominant disciplines with $25.3 \%$ and $12.9 \%$ of references respectively. The top six disciplines, based on published references from our literature search, were: Medicine, Engineering, Pharmacy, Nursing, Library \& Information Literacy, and Information Studies \& Information Science.

The search results showed more publications dealing with professional schools and the sciences, and fewer publications dealing with humanities. Several subjects and disciplines were not found in the literature search, such as language studies and history.

We recognize that this literature search represents only a snapshot, and subsequent web searches showed active curriculum maps in subjects and disciplines not listed in Table 1 . We also recognize that much curriculum mapping work is not published in the scholarly literature.

\section{Similarities and Differences in Curriculum Mapping: Approaches between Disciplines}

The departments from the University of Toronto Mississauga that are involved in the curriculum mapping initiative represent disciplines from Science, Social Science, and Humanities, as well as interdisciplinary programs. The departments that provided input to this article include Biology, Geography, Language Studies, and the Institute of Communication, Culture, Information and Technology (ICCIT). Throughout this curriculum mapping initiative, we noticed some disciplinespecific similarities and differences in the approaches to curriculum mapping. We noted that the similarities and differences could be classified according to several different themes: (1) the purpose and motivation for engaging in curriculum mapping; (2) the process of curriculum mapping; (3) the implementation and use of the curriculum maps; (4) terminology \& jargon; (5) faculty buy-in and support; and (6) curriculum map visualization and dissemination. We have summarized our key findings in Table 2.

\section{Purpose and Motivation for Engaging in Curriculum Mapping}

As the University of Toronto Mississauga recently adopted the Undergraduate Degree Level Expectations (UDLEs) as established by the Ontario Council of Academic Vice-Presidents, departments have been encouraged to describe how they meet these learning expectations, encouraging some departments to initiate curriculum mapping projects. All departments described here have shown an interest in clearly conveying this curricular information and an interest in identifying gaps. It also became clear that different disciplines sometimes had different motivations for participating in the curriculum mapping process. For example, the Department of Geography's initial motivation was to respond to the requirements of a national-level program accreditation process. Subsequently, motivation included a need to analyze course progression to identify competency gaps, and also to link outcomes with assessment.

For the Department of Biology, for which there is no national-level accreditation, the motivation for initiating the curriculum mapping process was driven by the desire of the faculty to track the development of student science process skills and other transferable skills. Biology also wanted to initiate discussion of threshold concepts: core, foundational, and gateway concepts that need to be understood to allow and support further learning in the discipline, akin to a portal (Meyer \& Land, 2005), and can open up novel ways of approaching a subject or thinking about a problem. Biology was also particularly interested in aligning learning outcomes with assessment to gain an understanding of the development of transferable skills and collecting data that would enable evidence-based decision making during curriculum committee meetings. 


\section{Table 2}

\section{Highlights of common ground as well as differences found between departments that participated in the curriculum mapping process.}

\begin{tabular}{|c|c|c|}
\hline Category & Common Ground & Differences \\
\hline $\begin{array}{l}\text { Purpose and } \\
\text { motivation for } \\
\text { engaging in curriculum } \\
\text { mapping }\end{array}$ & $\begin{array}{l}\text {-to analyze course progression } \\
\text { - to identify competency gaps } \\
\text {-to link outcomes with assessment } \\
\text { - to track the development of transferable } \\
\text { skills } \\
\text { - to examine how courses fit together to } \\
\text { create a coherent curriculum } \\
\text { - to align learning outcome progression } \\
\text { with Undergraduate Degree Learning } \\
\text { Expectations }\end{array}$ & $\begin{array}{l}\text { Geography/Environment: to respond to } \\
\text { national accreditation process } \\
\text { Biology: facilitate increased use of backwards } \\
\text { design; foster a reflective learning } \\
\text { community } \\
\text { Language Studies: align learning outcomes } \\
\text { with the Common European Framework of } \\
\text { Reference for Languages }\end{array}$ \\
\hline $\begin{array}{l}\text { Curriculum Mapping } \\
\text { Process }\end{array}$ & $\begin{array}{l}\text {-use faculty interviews in addition to } \\
\text { course syllabi } \\
\text { •track if learning outcomes are taught vs } \\
\text { assessed, and at which level (introduced, } \\
\text { reinforced, advanced) }\end{array}$ & $\begin{array}{l}\text { Biology: start with a faculty survey to create } \\
\text { a "data wishlist"; established a Biology Skill } \\
\text { Set and a set of knowledge frameworks that } \\
\text { would be mapped in addition to the } \\
\text { departmental learning outcomes } \\
\text { Language Studies: looked at assessments in } \\
\text { addition to course syllabi }\end{array}$ \\
\hline $\begin{array}{l}\text { Implementation / Use } \\
\text { of the Curriculum } \\
\text { Map }\end{array}$ & $\begin{array}{l}\text {-help faculty see how their courses fit } \\
\text { within the large program scheme } \\
\text { •use the map for future course planning }\end{array}$ & $\begin{array}{l}\text { Biology: use the map to guide evidence- } \\
\text { based decision making during curriculum } \\
\text { committee meetings; guide the use of } \\
\text { backwards design in course design and } \\
\text { renewal } \\
\text { ICCIT: use the map to guide faculty hire } \\
\text { decisions } \\
\text { Language Studies: use the map to re-write } \\
\text { all courses' syllabi to align learning } \\
\text { outcomes }\end{array}$ \\
\hline Terminology / Jargon & $\begin{array}{l}\text { •pedagogical jargon tends to be a barrier } \\
\text { across disciplines }\end{array}$ & $\begin{array}{l}\text { Biology: developed a pedagogical dictionary } \\
\text { that contained biology-specific examples. }\end{array}$ \\
\hline $\begin{array}{l}\text { Faculty Buy-In and } \\
\text { Support }\end{array}$ & $\begin{array}{l}\text {-increase faculty buy-in by showcasing } \\
\text { curriculum maps used by other } \\
\text { departments }\end{array}$ & $\begin{array}{l}\text { Biology: surveyed all faculty at the initiation } \\
\text { of the curriculum mapping process } \\
\text { ICCIT: high number of sessionals made } \\
\text { faculty buy-in challenging }\end{array}$ \\
\hline $\begin{array}{l}\text { Curriculum Map } \\
\text { Visualization and } \\
\text { Dissemination }\end{array}$ & $\begin{array}{l}\text { - most departments use excel to organize } \\
\text { their curricular data }\end{array}$ & \\
\hline
\end{tabular}


Additionally, several faculty members wanted to use the curriculum mapping process to foster a reflective learning community and initiate a dialogue between faculty of different courses, and faculty with a research vs teaching focus. This has been previously reported in the literature in teacher education (Bartoo, 2005).

Much like Biology, ICCIT needed to examine how the variety of courses fit together to create a coherent curriculum. The challenge with an interdisciplinary unit is to make the overall curriculum seem logical and coherent, thus it was important to see how the courses are connected. This had implications for the range of assessment tools and strategies used across four different programs and the integration of faculty research. The curriculum mapping exercise partly informed the direction for posting for new hires and helped to guide students trying to navigate their way through the multitude of course options and create a cohesive course of study. As with Biology, ICCIT wanted to focus on transferable skills development, link the curriculum map learning outcomes with assessment, align learning outcomes throughout the program, and identify gaps, inconsistencies, and areas for improvement.

In Language Studies, a core set of learning outcomes for both French for francophone courses and French as a second language courses were developed in order to ensure coherent progression between levels and more cohesively scaffolded assessment methods. Based on the Common European Framework of Reference for Languages (Council of Europe, 2002), Canadian Language Benchmarks (The Centre for Canadian Language Benchmarks, 2006), as well as the UDLEs (University of Toronto Mississauga, 2016), a steering committee identified and described more program-specific areas of competencies and "can do" statements for each level of the series - e.g., at the end of this course, you can "interact with other French speakers on topics related to your daily routines". This work aimed to harmonize FSL series learning outcomes, level of language skills and competencies, and assessment methods. While many reasons are similar to those mentioned in Biology and ICCIT, Language Studies had several additional reasons for engaging in the curriculum mapping process: (1) We wanted to make sure that our FSL series courses achieve similar level of competencies that other Canadian and International frameworks propose; (2) We wanted to guarantee that our students be able to compete in a real world; (3) We wanted to make sure repetitions, inherent to and necessary for language acquisition, are integrated in a cohesively progressive manner so that students do not just repeat the same materials from one level to the next one; (4) We wanted to evaluate logical progression in assessments that correspond accurately with materials taught in classes; (5) We wanted to collectively adopt more communicative and action-based pedagogical approaches; (6) We wanted to propose common grade distribution in all courses; and (7) We wanted to identify areas of improvement.

\section{Curriculum Mapping Process}

To initiate the curriculum mapping process, Biology surveyed faculty about what questions they had about the biology curriculum and how they would use the final curriculum map. As a faculty, Biology developed the "Biology Skill Set" that all students should be capable of upon graduation. This skill set as well as twelve departmental learning outcomes were mapped onto the curriculum of all courses. After discussing the results with faculty, questions were asked about knowledge content. Biology then developed six knowledge frameworks that were then mapped across all courses (Evolution, Genetics, Molecular Biology and Biotechnology, Animal Form and Function, Plant Form and Function, and Ecology). This resulted in three different curriculum maps that could be superimposed: a knowledge framework map, a skill set map, and a learning outcome map. Data for the maps was acquired through a review of course syllabi and interviews with course instructors. For each map element, instructors had to identify if it was taught and/or assessed, and at which level (introduced/reinforced/advanced) (as was done by Arafeh, 2016).

The ICCIT curriculum mapping project prompted a whole collection of activities. The first was to establish clear program outcomes and analyze 
how those outcomes distinguished one program from another; for example, how the learning outcomes for a communication, culture, and media course define a separate set of skills from a professional writing and communication course. This exercise highlighted the skills that were essential for all programs and then points of distinction. The exercise also highlighted the various career paths that students could take through the different streams of courses - an important factor for this particular interdisciplinary institute. The next step was to develop templates that corresponded to the learning outcomes and gather information. An additional goal of the mapping process was to create a coloured visualization that would highlight overlaps, gaps, and inconsistencies.

For Language Studies, it was decided that a curriculum committee would be formed to work on curriculum harmonization during summer months. The committee researched frameworks that could be used as theoretical underpinnings (e.g., CEFRL, Canadian Language Benchmarks, UDLEs). Collectively, the committee discussed several language teaching approaches and determined the most suitable ones for the particular needs of University of Toronto Mississauga students. Afterward, it collected and studied course syllabi and sample assessments at all year levels. Learning outcomes were categorized by competencies and reformulated in greater detail, and each course's learning outcomes were linked to implement a logical progression from level to level. The committee also decided on a grade distribution based on four main criteria: oral comprehension, oral production, written comprehension, and written production.

\section{Implementation/Use of the Curriculum map}

For Biology, the map is currently used to guide evidence-based decision making during curriculum committee meetings. We also use the map to guide the use of backwards design in course design and renewal. We are exploring ways to communicate this data-rich map to students and to use in advising sessions. We want to help students take responsibility for their own learning (Harden, 2001; Robley, Whittle, \& Murdoch-Eaton, 2005).

The first phase of the ICCIT curriculum map helped faculty to better see how their courses fit within the larger program scheme, and as a group, the coloured visualization of the map was useful for future planning as the Institute was relatively new and had undergone early growing pains and transformations. The mapping exercise demonstrated the need for continuous review of how the four programs were evolving and aligning as new hires and new courses were added. The long-term goal was to be able to use the mapping data with students so they could gain a better sense of how the courses fit together to scaffold their learning and achieve the expected outcomes. The intention was for students to gain more autonomy over their own course choices, affecting how they experienced learning within their program.

For Language Studies, findings and recommendations of the curriculum committee were communicated at the program level. Learning outcome tables for the whole program were used to re-write all course syllabi, which clearly underlined learning outcomes and course expectations across all courses. New textbooks in a series were selected to provide guidelines to instructors, and an organization website page was created as a depository of tests and exams which were re-evaluated to match course content and assessment.

\section{Terminology/Jargon}

Pedagogical jargon appeared to be a barrier to multiple departments at various stages of the curriculum mapping process. In order to deal with this jargon roadblock, Biology developed a pedagogical dictionary that contained biology examples. It was also clear that across disciplines, differences exist in the definition of assessment and assessment levels/forms. All departments found that naming the different "levels" in terms of introductory, developing/reinforcing, and advanced/competency was very important, but also 
challenging. Sometimes this appeared to be contextual in terms of program objectives, faculty expectations, and the assessment tools used.

\section{Faculty Buy-In and Support}

Diversity in disciplines is also represented in challenges, namely gaining faculty support and actual implementation at the course level. Geography was able to earn faculty buy-in by showcasing curriculum maps that were being used by other departments. Biology tried to increase faculty buy-in by surveying all faculty at the beginning and asking them what curricular questions they needed to be answered and then making sure to follow up with those answers after the mapping process. For Language Studies, due to existing frameworks and their adoption in many language programs and thanks to experts in education and second language acquisition in the department, a consensus on benefits and needs of curriculum mapping arrived without too much resistance. Complications would instead sometimes arise in the faculty's willingness to implement new learning outcomes and modify existing course curriculum. For ICCIT, faculty buy-in was an area that was most challenging due to the context (ICCIT includes joint programs and had a high number of sessionals during the initial mapping stage) and time. Collecting data from course syllabi was not enough. The second iteration of the ICCIT curriculum map will involve discussions with each instructor to gain more detailed information, and help them understand how they can use the collected data. Note that one other department had to drop out because of the lack of support from other faculty members.

\section{Curriculum Map Visualization and Dissemination.}

Biology explored numerous curriculum map visualization tools prior to collecting and disseminating any curricular data. Due to the complexity of the data set, and the desire to maintain the feasibility of updating the data set, Biology decided to use excel for all curricular data entry. Visualization of the curricular data consists of screen shots of colour coded Excel worksheets. We are currently developing approaches by which faculty and students will be able to interact directly with the curricular data and run their own queries of the dataset. ICCIT created a large colour coded map using an Excel file that was populated by information collected through a template distributed by email. The online collection of the data was efficient but lacked the kind of rich data that could be supplied through short face-to-face meetings. Language Studies entered their curricular data in table form similar to the CFERL's self-assessment grid for each level (Council of Europe, 2004), and detailed learning outcomes in an Excel worksheet. Having identified the need to visualize language learning progression in both spiral and scaffolded forms, the Department of Language Studies plans to extend its curriculum mapping process.

\section{Benefits of Curriculum Mapping}

All participating departments found that participating in the curriculum mapping process fostered a collaborative approach to discussing teaching and learning throughout the department, and it brought all faculty from both teaching stream and the research stream into the teaching and learning discussion. All departments identified that it helps with selection and planning of new courses, as well as the use of backwards design in course design and renewal. Similar to Biology and ICCIT, Language Studies found that curriculum mapping leads to establishing more coherent progression by bridging gaps between levels and courses. It also allows for repetitions of course content to be done in a more controlled fashion, and that assessment of students' competencies are aligned to each difficulty level. Also, graduating students can more accurately explain their competencies in professional contexts such as on a resume or during a job interview. 


\section{Cross-Disciplinary Collaboration for Curriculum Mapping}

We want to conclude by emphasizing that many of the attributes we want our students to master are common across all of our disciplines, and are not discipline specific. For example, students in ICCIT will not need to learn to do t-tests like students in Biology, but we want all students to have a basic level of information literacy and graphical literacy, and a basic understanding of the processes involved in research and inquiry. This brings us back to the UDLEs and the need for cross-disciplinary collaboration to ensure that these learning expectations are met across programs and across the university. The current curriculum mapping initiative is still in its early stages, but we have identified that developing a learning community between interested individuals from different departments facilitates curriculum mapping for all involved and helps to develop a large pool of resources. Also, the importance of starting with a set of learning outcomes and promoting backwards design has stood out as applying across all disciplines. For other institutions wanting to engage in crossdisciplinary curriculum mapping projects, we recommend that a common language be established, and a common set of well-defined metrics be identified (such as taught/assessed; introductory/ reinforced/advanced). Collaboration between departments also helps to develop more consistency in the process so that the data may be used more broadly by the institution in terms of meeting UDLEs and addressing graduate attributes required for the new work world both nationally and globally.

\section{References}

Acuña, T. B., Kelder, J.-A., Lane, P., Hannan, G., \& Jones, S. (2013). Developing threshold learning outcomes for agricultural science. International Journal of Innovation in Science and Mathematics Education, 21(5), 54-66. VIEW ITEM
Ahmad, A. (2015, June). Industrial engineering technology curriculum remapping. Paper presented at the 122nd ASEE Annual Conference and Exposition, Los Angeles, CA. VIEW ITEM

Arafeh, S. (2016). Curriculum mapping in higher education: A case study and proposed content scope and sequence mapping tool. Journal of Further \& Higher Education, 40(5), 585-611. VIEW ITEM

Archambault, S. G., \& Masunaga, J. (2015). Curriculum mapping as a strategic planning tool. Journal of Library Administration, 55(6), 503-519. VIEW ITEM

Baecher, L. (2012). Integrating clinical experiences in a TESOL teacher education program: Curriculum mapping as process. TESOL Journal, 3(4), 537-551. VIEW ITEM

Balzer, F., Hautz, W. E., Spies, C., Bietenbeck, A., Dittmar, M., Sugiharto, F., ... Ahlers, O. (2016). Development and alignment of undergraduate medical curricula in a webbased, dynamic Learning Opportunities, Objectives and Outcome Platform (LOOOP). Medical Teacher, 38(4), 369-377. VIEW ITEM

Bartoo, E. (2005). Getting results with curriculum mapping. Teachers College Record, 107(11), 2437-2443. VIEW ITEM

Bell, C. E., Ellaway, R. H., \& Rhind, S. M. (2009). Getting started with curriculum mapping in a veterinary degree program. Journal of Veterinary Medical Education, 36(1), 100-106. VIEW ITEM

Britten, N., Wallar, L. E., McEwen, S. A., \& Papadopoulos, A. (2014). Using core competencies to build an evaluative framework: Outcome assessment of the University of Guelph Master of Public Health 
program. BMC Medical Education, 14(1). VIEW ITEM

Britton, M., Letassy, N., Medina, M. S., \& Er, N. (2008). A curriculum review and mapping process supported by an electronic database system. American Journal of Pharmaceutical Education, 72(5). VIEW ITEM

Buchanan, H., Webb, K. K., Houk, A. H., \& Tingelstad, C. (2015). Curriculum Mapping in academic libraries. New Review of Academic Librarianship, 21(1), 94-111. VIEW ITEM

The Centre for Canadian Language Benchmarks. (2006). Niveaux de competences linguistiques canadiens: français langue seconde pour adultes. VIEW ITEM

Charles, L. H. (2015). Using an information literacy curriculum map as a means of communication and accountability for stakeholders in higher education. Journal of Information Literacy, 9(1), 47-61. VIEW ITEM

Cloutier, G., Hugo, R., \& Sellens, R. (2012). Mapping the relationship between the CDIO syllabus and the 2008 CEAB graduate attributes: An update. International Journal of Quality Assurance in Engineering and Technology Education, 2(2), 34. VIEW ITEM

Cottrell, S., Linger, B., \& Shumway, J. (2004). Using information contained in the Curriculum Management Information Tool (CurrMIT) to capture opportunities for student learning and development. Medical Teacher, 26(5), 423427. VIEW ITEM

Council of Europe, Language Policy Unit. (2002). Common European Framework of Reference for Languages: Learning, Teaching, Assessment. VIEW ITEM

Curtis, D. M., \& Moss, D. M. (2010). Curriculum mapping: Bringing evidence-based frameworks to legal education. Nova Law Review, 34, 473. VIEW ITEM

DeLuca, C., \& Bellara, A. (2013). The current state of assessment education: Aligning policy, standards, and teacher education curriculum. Journal of Teacher Education, 64(4), 356-372. VIEW ITEM

Ellaway, R. H., Albright, S., Smothers, V., Cameron, T., \& Willett, T. (2014). Curriculum inventory: Modeling, sharing and comparing medical education programs. Medical Teacher, 36(3), 208-215. VIEW ITEM

Figueroa, J. L., Birch, D. A., King, L. R., \& Cottrell, R. R. (2015). CEPH accreditation of standalone baccalaureate programs: A preliminary mapping exercise. Health Promotion Practice, 16(1), 115-121. VIEW ITEM

Fournier, K. (2014). How curriculum mapping can facilitate the integration of information literacy instructions in an undergraduate program. Journal of the Canadian Health Libraries Association / Journal de l'Association des Bibliothèques de La Santé Du Canada, 35(2), 113-114. VIEW ITEM

French, J., Shah, D., Rankin, J., Bagiati, A., \& Breslow, L. (2012). Identifying and mapping pivotal concepts and critical skills concept mapping a "freshmore" engineering curriculum. Paper presented at the SEFI 40th Annual Conference 2012, Cambridge, MA. VIEW ITEM

Gluga, R. (2010). Long term student learner modeling and curriculum mapping. In $\mathrm{V}$. Aleven, J. Kay, \& J. Mostow (Eds.), Lecture Notes in Computer Science: Vol. 6095. $10^{\text {th }}$ International Conference, ITS 2010 (pp. 227229). (including subseries Lecture Notes in Artificial Intelligence and Lecture Notes in Bioinformatics) VIEW ITEM 
Gorrell, L., Beirman, R. L., \& Vemulpad, S. R. (2015). Curriculum mapping within an Australian master of chiropractic program: Congruence between published evidence for chiropractic and student assessment tasks. Journal of Chiropractic Education, 29(1), 2936. VIEW ITEM

Harden, R. M. (2001). AMEE Guide No. 21: Curriculum mapping: A tool for transparent and authentic teaching and learning. Medical Teacher, 23(2), 123-137. VIEW ITEM

Harris, M. A., \& Patten, K. P. (2015). Using Bloom's and Webb's taxonomies to integrate emerging cybersecurity topics into a computing curriculum. Journal of Information Systems Education, 26(3), 219-234. VIEW ITEM

Hege, I., Nowak, D., Kolb, S., Fischer, M. R., \& Radon, K. (2010). Developing and analysing a curriculum map in occupational- and environmental medicine. BMC Medical Education, 10(1). VIEW ITEM

Joenathan, C., Bunch, R., \& Granieri, S. (2005). Optical engineering education with curriculum mapping for ABET accreditation. Proceedings of the $9^{\text {th }}$ International Topic Meeting on Education and Training in Optics and Photonics, 9664. VIEW ITEM

Johnson, C. C., Peters-Burton, E. E., \& Moore, T. J. (Eds.). (2015). STEM road map: A framework for integrated STEM education. VIEW ITEM

Karsten, R., \& Roth, R. M. (2015). A complementary measure of MIS program outcomes: Useful insights from a student perspective. Journal of Information Systems Education, 26(2), 155-164. VIEW ITEM

Keijsers, C. J. P. W., de Wit, J. E., Tichelaar, J., Brouwers, J. R. B. J., de Wildt, D. J., de Vries, P. G. M., \& Jansen, P. A. F. (2015). Education on prescribing for older patients in the Netherlands: A curriculum mapping.
European Journal of Clinical Pharmacology, 71(5), 603-609. VIEW ITEM

Kelley, K. A., McAuley, J. W., Wallace, L. J., \& Frank, S. G. (2008). Curricular mapping: Process and product. American Journal of Pharmaceutical Education, 72(5). VIEW ITEM

Komenda, M., Víta, M., Vaitsis, C., Schwarz, D., Pokorná, A., Zary, N., \& Dusek, L. (2015). Curriculum mapping with academic analytics in medical and healthcare education. PLoS One, 10(12). VIEW ITEM

Kopera-Frye, K., Mahaffy, J., \& Svare, G. M. (2008). The map to curriculum alignment and improvement. Collected Essays on Learning and Teaching, 1, 8-14. VIEW ITEM

Lam, B. -H., \& Tsui, K. -T. (2013). Examining the alignment of subject learning outcomes and course curricula through curriculum mapping. Australian Journal of Teacher Education, 38(12), 24. VIEW ITEM

Lamb, E. B. (2016). Best practices for career preparation in four undergraduate art programs (Doctoral dissertation). Retrieved from ProQuest Dissertations \& Theses database. (UMI No. 3704489)

Landry, L. G., Alameida, M. D., Orsolini-Hain, L., Boyle, A. R., Privé, A., Chien, A., ... Leong, A. (2011). Responding to demands to change nursing education: Use of curriculum mapping to assess curricular content. Journal of Nursing Education, 50(10), 587-590. VIEW ITEM

Liu, Y. -L., Chen, T. -L., Yueh, H. -P., \& Sheen, H. -J. (2014). Exploring competencies of nanotechnology in higher education in Taiwan through curriculum mapping. International Journal of Engineering Education, 30(3), 722728. VIEW ITEM 
Mackie, P. F. -E., \& Anderson, W. A. (2011). Reinventing baccalaureate social work program assessment and curriculum mapping under the 2008 EPAS: A conceptual and quantitative model. The Journal of Baccalaureate Social Work, 16(1), 1-16. VIEW ITEM

MacNeil, C. \& Hand, T. (2014). Examining occupational therapy education through faculty engagement in curriculum mapping and pedagogical reflection. The American Journal of Occupational Therapy, 68, S12-S22. VIEW ITEM

Malone, D. T., Short, J. L., Naidu, S., White, P. J., \& Kirkpatrick, C. M. (2015). Mapping of the Australian Qualifications Framework Standards onto an undergraduate bachelor of pharmacy course. Pharmacy Education, 15(1), 261-269. VIEW ITEM

May, C. (2012). A curriculum map of colorectal surgery: An assessment of training expectations and the reality. BMC Proceedings, 6(Suppl 4). VIEW ITEM

Mazurat, R., \& Schönwetter, D. J. (2008). Electronic curriculum mapping: Supporting competencybased dental education. Journal of the Canadian Dental Association, 74(10), 886889. VIEW ITEM

McGrath, D. (2010). What do we mean by ICT graduate attributes? Exploring mappings to course objectives. In C. H. Steel, M. J. Keppel, P. Gerbic, \& S. Housego (Eds.), Curriculum, technology \& transformation for an unknown future. The 27th Annual Conference of the Australasian Society for Computers in Learning in Tertiary Education, ASCILITE (pp. 604 608). Sydney, NSW. VIEW ITEM

Merritt, B. K., Blake, A. I., McIntyre, A. H., \& Packer, T. L. (2012). Curriculum evaluation: Linking curriculum objectives to essential competencies. The Canadian Journal of
Occupational Therapy, 79(3), 175-180. VIEW ITEM

Meyer, J. H. F., \& Land, R. (2005). Threshold concepts and troublesome knowledge (2): Epistemological considerations and a conceptual framework for teaching and learning. Higher Education, 49(3), 373-388. VIEW ITEM

Miller, M., \& Neyer, L. (2016). Mapping information literacy and written communication outcomes in an undergraduate nursing curriculum: A case study in librarianfaculty collaboration. Pennsylvania Libraries, 4(1), 20-32. VIEW ITEM

Narayanasamy, A., Jurgens, F., Narayanasamy, M., \& Guo, P. (2013). Diversity project: Mapping of diversity teaching and learning in nurse education curriculum. Journal of Further \& Higher Education, 37(4), 536-551. VIEW ITEM

Perlin, M. S. (2011). Curriculum mapping for program evaluation and CAHME accreditation. Journal of Health Administration Education, 28(1), 33-53. VIEW ITEM

Plaza, C. M., Draugalis, J. R., Slack, M. K., Skrepnek, G. H., \& Sauer, K. A. (2007). Curriculum mapping in program assessment and evaluation. American Journal of Pharmaceutical Education, 71(2). VIEW ITEM

Pratt, J. A., Keys, A., \& Wirkus, T. (2014). Preparing information systems graduates for a complex society: Aligning IS curricula with liberal education learning outcomes. Journal of Information Systems Education, 25(1), 35-44. VIEW ITEM

Ranade, S. M., Ortiz, R. V., Eliecer, J., Gómez, R., Carlos, J., \& Montaño, R. (2011, April). Refinery operators and maintenance technicians: Mapping competencies. Chemical Engineering, 118(4), 54-58. VIEW ITEM 
Regier, K. F. (2015). Equivalency of general biology (for majors) across a state-system (Doctoral Dissertation). Retrieved from ProQuest Dissertations \& Theses database. (UMI No. 3667236)

Reid, J., \& Wilkes, J. (2016). Developing and applying quantitative skills maps for STEM curricula, with a focus on different modes of learning. International Journal of Mathematical Education in Science \& Technology, 47(6), 837852. VIEW ITEM

Robley, W., Whittle, S., \& Murdoch-Eaton, D. (2005). Mapping generic skills curricula: Outcomes and discussion. Journal of Further and Higher Education, 29(4), 321-330. VIEW ITEM

Rowley, J., \& Dunbar-Hall, P. (2012). Curriculum mapping and ePortfolios: Embedding a new technology in music teacher preparation. Australian Journal of Music Education, 1, 2231. VIEW ITEM

Saad, I. M. H. (2014, June). Mapping the curriculum around student learning outcomes and assessment of learning. Paper presented at the 121st ASEE Annual Conference and Exposition: 360 Degrees of Engineering Education, Indianapolis, IN. VIEW ITEM

Spronken-Smith, R., McLean, A., Smith, N., Bond, C., Jenkins, M., Marshall, S., \& Frielick, S. (2016). A toolkit to implement graduate attributes in geography curricula. Journal of Geography in Higher Education, 40(2), 254266. VIEW ITEM

Stanny, C. J. (2015). Assessing the psychology curriculum: A primer for faculty and administrators. In D. S. Dunn (Ed.), The Oxford handbook of undergraduate psychology education (pp. 813-831). New York, NY: Oxford University Press.
University of Toronto Mississauga. (2016). Guidelines for University of Toronto Mississauga Undergraduate Degree Level Expectations (2016). VIEW ITEM

Valerius, J. D., \& Hersh, W. R. (2008, November). How well does a biomedical informatics curriculum map to health information management knowledge clusters? Analysis of a program. Paper presented at the AMIA ... Annual Symposium Proceedings. VIEW ITEM

Veltri, N. F., Webb, H. W., Matveev, A. G., \& Zapatero, E. G. (2011). Curriculum mapping as a tool for continuous improvement of IS curriculum. Journal of Information Systems Education, 22(1), 31-42. VIEW ITEM

Wang, L., \& Ashcraft, R. F. (2012). Needs assessment and curriculum mapping: Enhancing management skills of the nonprofit workforce. Nonprofit Management and Leadership, 23(1), 121-136. VIEW ITEM

Wardle, K., Ruddlesdin, J., Wentworth, L., Bhat, S., Baker, P., \& Roberts, N. (2011). The use of curriculum mapping in evaluating a regional geriatric training programme. CME Journal Geriatric Medicine, 13(3), 85-91. VIEW ITEM

Watts, L., \& Hodgson, D. (2015). Whole curriculum mapping of assessment: Cartographies of assessment and learning. Social Work Education, 34(6), 682-699. VIEW ITEM

Willett, T. G. (2008). Current status of curriculum mapping in Canada and the UK. Medical Education, 42(8), 786-793. VIEW ITEM

Williams, J., \& Bolland, K. (2011). Mapping our way to success. The Journal of Baccalaureate Social Work, 16(2), 93-114. VIEW ITEM

Wong, R. Y., \& Roberts, J. M. (2007). Real time curriculum map for internal medicine 
residency. BMC Medical Education, 7(1), 42. VIEW ITEM

Zelenitsky, S., Vercaigne, L., Davies, N. M., Davis, C., Renaud, R., \& Kristjanson, C. (2014). Using Curriculum Mapping to Engage Faculty Members in the Analysis of a Pharmacy Program. American Journal of Pharmaceutical Education, 78(7), 139. VIEW ITEM

\section{Acknowledgements}

Thanks go to Mindy Thuna, liaison librarian, for peer-reviewing search strings and literature search approach, and also to Cleo Boyd for constant guidance and support in developing our curriculum mapping learning community.

\section{Biography}

Fiona Rawle is an Associate Professor in the Teaching Stream of the Dept. of Biology at UTM.

Tracey Bowen is an Assistant Professor in the Teaching Stream of the Institute of Communication, Culture, Information and Technology at UTM.

Barbara Murck is an Associate Professor in the Teaching Stream of the Dept. of Geography at UTM.

Rosa Junghwa Hong is an Assistant Professor in the Teaching Stream of the Dept. of Language Studies at UTM. 